\title{
Peginterferon alfa-2b Regimen
}

National Cancer Institute

\section{Source}

National Cancer Institute. Peginterferon alfa-2b Regimen. NCI Thesaurus. Code

C160107.

A chemotherapy regimen consisting of peginterferon alfa- $2 \mathrm{~b}$ that may be used in the treatment of myeloproliferative neoplasms and systemic mastocytosis. 